\title{
Hyperelastic tape modifies the kinematics of the pronated foot in young women: self-controlled clinical trial
}

\section{A bandagem hiperelástica modifica a cinemática do pé pronado em mulheres jovens: ensaio clínico autocontrolado}

\author{
Maikon Gleibyson Rodrigues dos Santos [Da,b], Darlan Martins Ribeiro (iD [c,d], \\ José Roberto de Souza Junior (iD [a], Maykon Lacerda de Santana (Dic], Thiago Vilela Lemos (iD [d], \\ João Paulo Chieregato Matheus $\mathbb{B}[\mathrm{a}] *$
}

[a] Universidade de Brasília (UnB), Brasília, DF, Brazil

[b] Centro Universitário Estácio de Brasília, Brasília, DF, Brazil

[c] Centro Estadual de Reabilitação e Readaptação Dr. Henrique Santillo (CRER), Goiânia, GO, Brazil

[d] Universidade Estadual de Goiás (UEG), Goiânia, GO, Brazil

\begin{abstract}
Introduction: Excessive pronation has been linked to increased risk of developing lower limb injuries. In this respect, assessing the effectiveness of therapeutic resources, such as hyperelastic taping, becomes relevant. Objective: evaluate the influence of adhesive hyperelastic taping on excessive pronation of the anklefoot complex in young women. Method: Self-controlled clinical trial of ten women with excessive pronation (Foot Posture Index $\geq 6$ ). Three-dimensional gait was assessed according to the Vicon Oxford Foot Model before and after taping. Hyperelastic tape was applied on the side with greater pronation (experimental side) and the opposite side was used as control (control side). The segments evaluated were the hindfoot, midfoot and forefoot. The Shapiro-Wilk normality, paired $t$ and Wilcoxon tests were applied and Significance was set at $\mathrm{p}<0.05$. Results: No change ( $\mathrm{p}>0.05$ ) was observed in the hindfoot on the experimental or control side;
\end{abstract}

\footnotetext{
*MGRS: MS, e-mail: maikongleibyson@hotmail.com DMR: MS, e-mail: darlan.ribeiro@hotmail.com

JRSJ: Doctoral Student, e-mail: joserobertofisio@gmail.com

MLS: MS, e-mail: maykon_lacerda@hotmail.com

TVL: PhD, e-mail: tvlemos@gmail.com

JPCM: PhD, e-mail: jpcmatheus@unb.br
} 
the midfoot showed a decrease in arch height $(\mathrm{p}<0.05)$ only on the experimental side; forefoot eversion ( $\mathrm{p}$ $<0.05$ ) declined only on the experimental side. Conclusion: The use of hyperelastic tape reduced forefoot eversion; however, this decrease is not clinically desirable, since excessive pronation in a closed chain increased in the sample of young women studied.

Keywords: Foot. Pronation. Gait. Athletic Tape.

\section{Resumo}

Introdução: A pronação excessiva tem sido relacionada ao aumento do risco de desenvolver lesões nos membros inferiores. Nesse sentido, verificar a efetividade de recursos terapêuticos, como a bandagem hiperelástica, tornou-se relevante. Objetivo: Avaliar a influência da bandagem hiperelástica na pronação excessiva do pé em mulheres jovens. Método: Ensaio clínico autocontrolado, no qual participaram dez mulheres com pronação excessiva (Foot Posture Index $\geq 6$ ). Realizou-se então a avaliação tridimensional da marcha de acordo com o modelo Oxford Foot Model da Vicon em dois momentos: antes e após a bandagem. Foi aplicada bandagem hiperelástica no lado com maior pronação (lado experimental) e o lado oposto foi utilizado como controle (lado controle). Quanto aos segmentos avaliados, estes foram o retropé, antepé e mediopé. Para análise dos dados aplicou-se o teste de normalidade Shapiro Wilk, testes t pareado e Wilcoxon. E o nível de significância foi considerado como $p<0,05$. Resultados: No retropé não foi verificada mudança $(p>0,05)$ no lado experimental ou controle; no mediopé foi observado redução da altura do arco $(p<0,05)$ somente no lado experimental, porém sem diferença entre grupos ( $p>0,05)$; e no antepé foi observado redução da eversão $(p<0,05)$ somente no lado experimental. Conclusão: A aplicação utilizada de bandagem hiperelástica reduziu a eversão do antepé, porém essa redução não é desejável clinicamente, uma vez que em cadeia fechada a pronação excessiva aumenta na amostra de mulheres jovens estudadas.

Palavras-chave: Pé. Pronação. Marcha. Bandagem Elástica Adesiva.

\section{Introduction}

Foot pronation is a physiological movement that performs two important functions: absorbing part of the load applied to the lower limbs and accumulating a certain elastic potential for propulsion [1-3]. Foot pronation can be defined as "Motion of the foot articulations that allow it to become more prone to the support surface, thereby increasing the ground contact surface area of the foot." [4].

This pronation can be excessive, exhibiting the following kinematic characteristics: initial contact with the everted hindfoot, loading response and mid-stance phase with marked midfoot depression (flattening of the medial longitudinal arch), terminal stance and pre-swing, with inverted and excessively adducted forefoot $[2,5,6]$.

This movement dysfunction shows a prevalence of 24 to $75 \%$ in studies conducted with US military personnel $[7,8]$. It can cause problems [2], such as medial tibial stress syndrome $[5,9]$, foot pain $[10,11]$ and anterior cruciate ligament injury $[12,13]$. Excessive pronation can also increase the frontal plane projection of the knee angle (dynamic valgus) $[14,15]$, which is related to the development of anterior knee pain [16]. All of the clinical repercussions of individuals with excessive pronation raise healthcare costs [7].

Given that the development of these clinical conditions may be linked to excessive pronation, there is a need for interventions in order to minimize it. In this respect, several therapeutic resources can be used, including therapeutic tapes. Of these, hyperelastic tape stands out, since, according to developers, it can decelerate movement, absorb load and generate mechanical assistance. This is due to the high degree of stretching (>200\%) and strong elastic resistance [17]; however, to date, no clinical trials or studies on materials that confirm these characteristics. With respect to pronation control, it has been reported that it can impede medial 
longitudinal arch flattening, but no result has confirmed this effect [17].

Thus, there is an important dearth of research on the use or not of this technique, since no clinical trials or published studies that investigated the effects of this resource on excessive pronation were found. Considering the need to determine the effect of taping on excessive pronation, the aim of this study was to verify the influence of hyperelastic taping on excessive foot pronation in young women.

\section{Method}

\section{Data extraction}

Self-controlled clinical trial conducted according to CONSORT (Consolidated Standards of Reporting Trials) guidelines (Figure 1) and registered in the Brazilian Registry of Clinical Trials, under the number RBR-9MVGRQ.

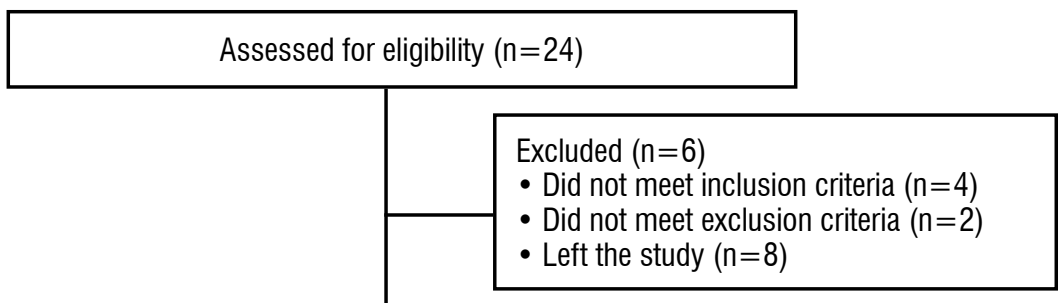

lower limb with small excessive pronation $(n=18)$

- Allocated to controls $(n=10)$

- Not allocated to intervention (provide reasons) $(n=0)$

Allocated to intervention -

lower limb with high excessive pronation $(n=18)$

- Allocated to intervention $(n=10)$

- Not allocated to intervention (give reasons) $(n=0)$

Follow-up

Study losses (participants left due to the length of time spent on assessment) $(\mathrm{n}=8)$

Intervention discontinued (give reasons) $(n=0)$

Analyzed $(n=10)$

- Excluded from analysis (give reasons) $(n=0)$

Figure 1 - CONSORT 2010 Flowchart.

\section{Ethical aspects}

The study was approved by the Ethics Committee of Pontifícia Universidade Católica in Goiás state, via the Brasil platform, under protocol number 1.450.171 and CAAE number 53240515.2.0000.0037.

\section{Subjects}

The study participants were recruited at Universidade Estadual de Goiás in Goiás state, Brazil.
Study losses (participants left due to the length time spent on assessment) $(\mathrm{n}=8)$

Intervention discontinued (give reasons) $(n=0)$

Analyzed $(n=10)$

- Excluded from analysis (give reasons) $(n=0)$

The inclusion criteria were age between 18 and 30 years, body mass index between 18.6 and $24.9 \mathrm{~kg} / \mathrm{m}^{2}$ and exhibiting at least one pronated foot in the Foot Posture Index (FPI $\geq 6$ ). The exclusion criteria were a history of surgery and/or trauma in the lower limbs in the last six months; allergy to the hyperelastic tape; recent or current treatment for excessive midfoot pronation; skin diseases, malignancies or bacterial infections at the tape application site; taking medication that compromises balance; and having ingested alcoholic beverages in the 48 hours before assessment. 
Intervention

The technique was applied to the lower limb with the highest degree of pronation (experimental side-ES) and the contralateral limb received no intervention (control side - CS). Before the tape was applied, the skin was cleaned with a paper towel and $70 \%$ alcohol used for sterilizing procedures.

The hyperelastic tape (Dynamic Tape ${ }^{\circledR}$ ) was applied with the foot and ankle in dorsiflexion, inversion and maximum adduction. Application consisted of an initial anchor (without stretching), elastic tension zone (stretch of 9 Newtons) and final anchor (no stretching). Since the initial anchor was attached between the first and fifth metatarsal bone on the dorsum of the foot, the elastic tension zone started along the side of the foot, crossing the navicular tuberosity and the anterior tibial muscle, with the final anchor ( $5 \mathrm{~cm}$ long) attached to the upper third of the leg. Tape stretching was measured with a tubular dynamometer (Cidepe ${ }^{\circledR} ; \mathrm{EQ} 007.10 \mathrm{~N}$ ), as suggested in an earlier study [18].

The type of application and direction of the technique were selected due to their widespread use in clinical practice to raise the arch and reduce excessive pronation, albeit without scientific proof to date. In addition, this technique was described in a previously published research protocol [19].

\section{Procedures}

The study procedures were carried out at the Laboratory of Movement of Centro Estadual de Reabilitação e Readaptação Dr. Henrique Santillo - CRER, in the city of Goiânia, Goiás state, Brazil. Two researchers collected the data, the first conducted the interviews, physical assessment, placed the reflective markers and applied the technique, while the second processed the data and collected range of motion measures. Only the reflective marker signals could be visualized on the computer screen, but not which leg the tape was applied to, and in order to guarantee rater blinding, data processing was performed after the assessment.

After written informed consent was obtained and subjects were assessed for inclusion/exclusion criteria, the subjects' weight $(\mathrm{kg})$, height $(\mathrm{m})$, body mass index (kg/ $\mathrm{m}^{2}$ ), age (years) and foot posture (FPI) were measured. FPI was assessed by a single physiotherapist trained during the pilot study. The test is applied with the participant in a comfortable upright position and 6 ankle-foot domains are observed: 3 in the hindfoot, 2 in the midfoot and 1 in the forefoot. For each domain, a score varying from -2 to +2 is attributed, and at the end of the test, all the domains are added, resulting in a final score between -12 and +12 . Values between 0 and +5 are considered a normal foot, < 0 supinated and $>5$ pronated [20]. Intrarater reliability of the total testscore was previously determined as moderate to high (ICC of 0.66 with CI between 0.45 and 0.82 ), and interrater reliability was also moderate to high (ICC of 0.79 with $\mathrm{CI}$ between 0.64 and 0.88) [21].

In addition, pelvis, knee and malleolar width, lower extremity length and tibial torsion angle were measured to feed the movement analysis system.

To capture three-dimensional images, reflective markers ( $8 \mathrm{~mm}$ in diameter) were attached to the skin according to the Oxford Foot Model (OFM) (Figure 2) [22]. A laser level was used to align the markers (Figure 2), and all the assessments were conducted by a single researcher. None of the markers were removed during the intervention.
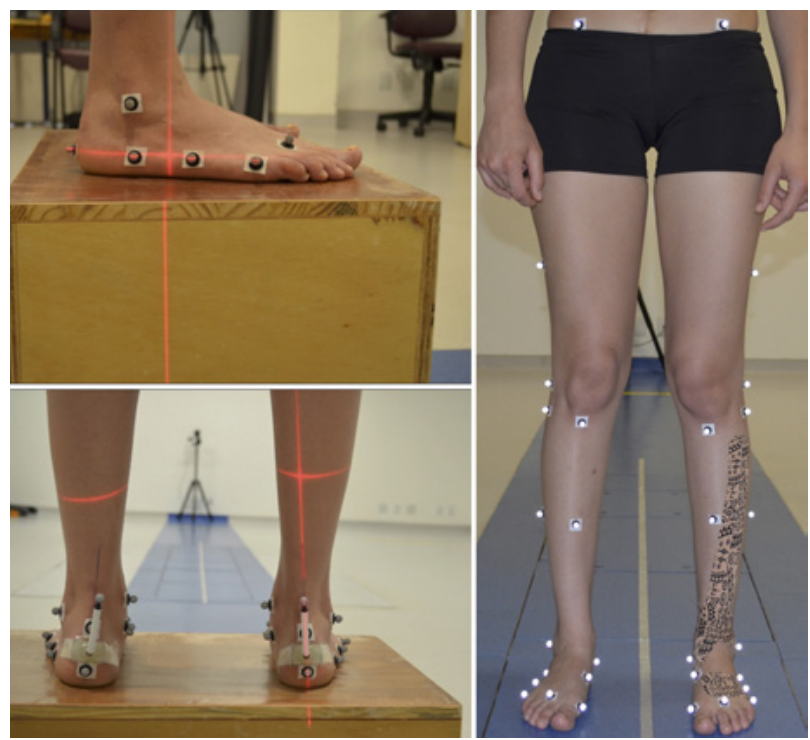

Figure 2 - OFM (Oxford Foot Model) assessment model and application of hyperelastic tape. Source: the authors.

Filming took place during self-selected gait, with subjects walking barefoot on an 8-meter track. Participants walked over 4 force platforms (AMTI ${ }^{\circledR}$ model OR6; OR7) placed along the track. Ten Vicon T-40 cameras were used for data collection of at least 5 trials. Gait was recorded pre and post tape application.

Gait data were processed with Vicon Nexus (version 1.8.5), Vicon Polygon (version 4.3) and Microsoft Excel (version 2011) software by a rater blinded investigator. The collection rate of the image capture system was $120 \mathrm{~Hz}$ and the following filters/methods were applied during data processing: Fill gaps, Replace4 on the pelvis, 4 th order Butterworth with a cutoff frequency of $10 \mathrm{~Hz}$ 
(analog devices, trajectories and model outputs) and the Woltring filtering routine. The equipment and software used to analyze movement were developed by Vicon (Oxford Metrics Ltd., UK).

\section{Variables}

The following kinematic data were used: hindfoot inversion and eversion relative to the leg, inversion and eversion of the forefoot relative to the hindfoot and medial longitudinal arch (MLA) height normalized by foot size. These data were arranged on the $\mathrm{Y}$ axis and gait cycle progression (\%) on the $\mathrm{X}$ axis.

Arch height (mm) was calculated with the software as follows: the distance between the marker at the base of the first metatarsus and the forefoot plane. A movement plane is formed by at least three reflective markers and in the case of the forefoot, formed by the markers at the base of the proximal phalanx of the hallux, and the base and head of the fifth metatarsus [23].

Arch deformation was used during loading response (0-10\% of the gait cycle). This is the result of subtracting the lowest arch height from the highest during loading response [24], as shown in Figure 3.
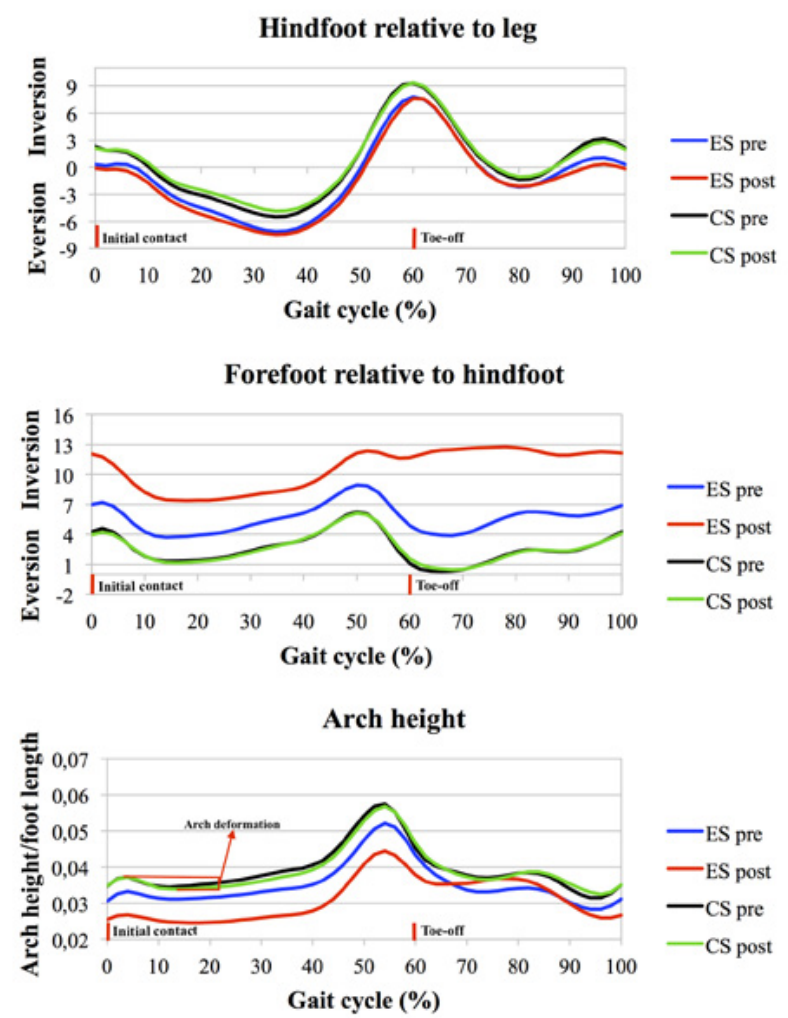

Figure 3 - Kinematic graphs of the hindfoot, forefoot and medial longitudinal arch index.

Note: ES - experimental side; CS - control side. Source: the authors.
Statistical analysis

The estimated sample size was 24 individuals (sampling calculation). A total population of 560 individuals was considered, applying a 5\% sampling error, 95\% confidence level and maximum percentage of $24 \%$ (prevalence of excessive pronation) [7].

In statistical analysis of the results, the Shapiro-Wilk normality test was applied to determine data dispersion. The parametric data were submitted to the paired t-test for intragroup comparison or independent t-test for intergroup comparison (mean and standard deviation). The nonparametric data were used in the Wilcoxon test for intragroup comparison or the Mann-Whitney U test for intergroup comparison (median and interquartile), and the significance level was set at 0.05 . The effect size was calculated as follows: $\mathrm{dz}=\mathrm{t} / \sqrt{\mathrm{n}}(\mathrm{dz}-$ effect size, $\mathrm{t}$ - the $\mathrm{t}$-test value observed, $\mathrm{n}$ - sample size), parametric data (0.2 - small, 0.5 - medium and 0.8 - large) [25]; $r=Z / \sqrt{2} \times n$ ( $r$ - effect size, $Z$ - the Wilcoxon test value observed, $\mathrm{n}$ - sample size), nonparametric data (0.1 - small, 0.3 - medium and 0.5 - large) [26]. The Statistical Package for the Social Sciences version 23.0 and Microsoft Excel version 14.2.5 were used.

\section{Results}

The study initiated with 18 participants, but 8 left over the course of the experiment. Thus, the final sample consisted of 10 women, whose descriptive characteristics are shown in Table 1.

Table 1 - Descriptive characteristics of the study participants

\begin{tabular}{lcc}
\hline & $\begin{array}{c}\text { Mean } \begin{array}{c}\text { Cstandard } \\
\text { deviation }\end{array} \\
\text { Age (years) }\end{array}$ & $\begin{array}{c}\text { Confidence } \\
\text { interval 95\% }\end{array}$ \\
Weight $(\mathrm{kg})$ & $22 \pm 2$ & $20.79-23.81$ \\
Height $(\mathrm{m})$ & $57.63 \pm 8.83$ & $51.31-63.95$ \\
BMI $\left(\mathrm{kg} / \mathrm{m}^{2}\right)$ & $1.64 \pm 0.08$ & $1.58-1.69$ \\
FPI ES & $21.49 \pm 2.5$ & $19.70-23.28$ \\
FPI CS & $8 \pm 2$ & $6.50-9.70$ \\
\hline
\end{tabular}

Note: BMI - body mass index; FPI - foot posture index; ES - experimental side, CS - control side. Source: the authors.

Table 2 shows intragroup and intergroup comparisons for measures of the hindfoot, forefoot and medial longitudinal arch height. With respect to the hindfoot, no significant difference was 
observed between pre and post initial contact, intergroup difference was observed on any of the toe-off and maximum eversion during stance. No sides assessed.

Table 2 - Hindfoot and forefoot range of motion and arch height before and after the intervention

\begin{tabular}{|c|c|c|c|c|c|c|}
\hline & & Pre & Post & & & \\
\hline & & Mean \pm SD & Mean \pm SD & $\begin{array}{l}\text { Difference } \\
\text { (post - pre) }\end{array}$ & $p$ & Effect Size \\
\hline & \multicolumn{6}{|c|}{ Hindfoot in the frontal plane: inversion $(+) /$ eversion(-), in degrees $\left({ }^{\circ}\right)$} \\
\hline \multirow[t]{4}{*}{ Initial contact } & ES & $0.33 \pm 3.7$ & $-0.11 \pm 4.24$ & -0.43 & 0.17 & 0.47 \\
\hline & CS & $2.27 \pm 3.9$ & $2.08 \pm 3.41$ & -0.19 & 0.56 & 0.19 \\
\hline & $p$ & 0.27 & 0.21 & & & \\
\hline & Effect Size & & 0.4 & & & \\
\hline \multirow[t]{4}{*}{ Toe-off } & ES & $7.04 \pm 4.09^{\mathrm{M}}$ & $5.76 \pm 5.25^{\mathrm{M}}$ & -1.28 & 0.51 & 0.15 \\
\hline & CS & $8.89 \pm 4.16^{\mathrm{M}}$ & $8.34 \pm 3.3^{\mathrm{M}}$ & -0.55 & 0.70 & 0.06 \\
\hline & $p$ & 0.21 & 0.16 & & & \\
\hline & Effect Size & 0.29 & 0.31 & & & \\
\hline \multirow[t]{2}{*}{$\begin{array}{l}\text { Maximum eversion } \\
\text { during stance }\end{array}$} & ES & $-5.97 \pm 3.32^{\mathrm{M}}$ & $-6.74 \pm 4.76^{\mathrm{M}}$ & -0.77 & 0.39 & 0.19 \\
\hline & $\begin{array}{c}C S \\
p \\
\text { Effect Size }\end{array}$ & $\begin{array}{c}-5.67 \pm 2.33 \\
0.31 \\
0.23\end{array}$ & $\begin{array}{c}-5.06 \pm 2.34 \\
0.14 \\
0.34\end{array}$ & 0.61 & 0.08 & 0.62 \\
\hline \multicolumn{7}{|c|}{ Forefoot in the frontal plane: inversion(+)/eversion(-), in degrees $\left({ }^{\circ}\right)$} \\
\hline \multirow[t]{4}{*}{ Initial contact } & ES & $7.00 \pm 5.24$ & $12.04 \pm 4.77$ & 5.04 & $<0.001^{*}$ & 2.26 \\
\hline & CS & $4.27 \pm 2.53$ & $3.96 \pm 2.73$ & -0.31 & 0.26 & 0.38 \\
\hline & $p$ & 0.15 & $<0.001^{*}$ & & & \\
\hline & Effect Size & 0.47 & 1.47 & & & \\
\hline \multirow{4}{*}{ Toe-off } & ES & $4.07 \pm 8.88^{\mathrm{M}}$ & $10.26 \pm 5.26^{\mathrm{M}}$ & 6.19 & $0.005^{\star}$ & 0.63 \\
\hline & CS & $1.15 \pm 2.88$ & $1.57 \pm 2.92$ & 0.42 & 0.08 & 0.62 \\
\hline & & 0.11 & $<0.001^{*}$ & & & \\
\hline & Effect Size & 0.37 & 0.83 & & & \\
\hline \multirow{5}{*}{$\begin{array}{l}\text { Maximum eversion } \\
\text { during stance }\end{array}$} & ES & $3.35 \pm 5.9 \mathrm{M}$ & $6.94 \pm 4.22 \mathrm{M}$ & 3.59 & $0.005^{\star}$ & 0.62 \\
\hline & CS & $1.22 \pm 2.27$ & $1.06 \pm 2.24$ & -0.16 & 0.37 & 0.30 \\
\hline & $p$ & 0.32 & $<0.001^{\star}$ & & & \\
\hline & Effect Size & 0.23 & 0.79 & & & \\
\hline & \multicolumn{6}{|c|}{ Medial longitudinal arch height normalized by foot size } \\
\hline \multirow[t]{4}{*}{ Initial contact } & ES & $0.030 \pm 0.013$ & $0.025 \pm 0.010$ & -0.005 & $0.02^{\star}$ & 0.91 \\
\hline & CS & $0.035 \pm 0.014$ & $0.035 \pm 0.014$ & 0 & 0.90 & 0.04 \\
\hline & $p$ & 0.49 & 0.11 & & & \\
\hline & Effect Size & 0.22 & 0.52 & & & \\
\hline \multirow[t]{4}{*}{ Toe-off } & ES & $0.044 \pm 0.013$ & $0.038 \pm 0.011$ & -0.006 & $0.02^{\star}$ & 0.94 \\
\hline & CS & $0.046 \pm 0.013$ & $0.048 \pm 0.015$ & 0.002 & 0.40 & 0.28 \\
\hline & $p$ & 0.71 & 0.11 & & & \\
\hline & Effect Size & 0.11 & 0.52 & & & \\
\hline \multirow{4}{*}{$\begin{array}{l}\text { Arch deformation } \\
\text { during stance }\end{array}$} & ES & $0.004 \pm 0.002$ & $0.005 \pm 0.004$ & 0.001 & 0.19 & 0.45 \\
\hline & CS & $0.004 \pm 0.004$ & $0.006 \pm 0.004$ & 0.002 & 0.07 & 0.66 \\
\hline & $p$ & 0.49 & 0.54 & & & \\
\hline & Effect Size & 0.22 & 0.20 & & & \\
\hline
\end{tabular}

Note: standard deviation, ES - experimental side, CS - control side, $M$ - median and interquartile range, *statistically significant $(p<0.05)$. Source: the authors. 
Figure 3 presents the ES and CS graphs of pre- and post-application for the hindfoot, forefoot and MLA height. The pre-and post-application hindfoot measures on the ES and CS were similar. The graph illustrating hindfoot kinematics shows a decline in eversion (more positive value), during stance and balance. On the MLA height graph, height was lower during all the stance phases on the ES at post-application compared to pre and the CS.

\section{Discussion}

The aim of the present study was to determine the influence of hyperelastic taping on excessive pronation of the foot in young women. We underscore the originality of the research, since it is the first to investigate the effect of hyperelastic taping as a three-dimensional assessment tool for foot movements.

In regard to the method used to quantify foot range of motion, moderate and good reproducibility values were found $(0.71-0.97)$ for the frontal plane and good (0.92 - 0.95) for the sagittal plane [27]. Since the most accurate values were recorded in these planes, inversion/eversion movements and the MLA index were assessed in the frontal and sagittal plane, respectively.

In terms of results, this study obtained two main findings: the first is a decrease in the eversion movement of the forefoot relative to the hindfoot throughout the gait cycle after the use of the tape; the second is the conservation of the same hindfoot movement characteristics in terms of the tibia before and after tape application.

However, few studies that used hyperelastic tape as a resource (Dynamic Taping ${ }^{\mathrm{TM}}$ ) exhibit acceptable methodological quality. Only one of the studies found is related to excessive pronation and used an application technique that was similar to that employed here. However, that study is a research protocol with no published results [19].

The first finding of this study, the decline in forefoot eversion, does not corroborate the results of a double-blind quasi-randomized clinical trial. The trial compared an experimental group with a placebo and found no changes in foot posture after elastic tape was applied to the hindfoot at $100 \%$ tension. A number of methodological differences hinder comparing their results with ours, such as the type of material used, the fact that the intervention was conducted with the hindfoot and failure to perform comparative analysis before and after tape application [28]. By contrast, another study observed a change in the forefoot after the use of elastic tape during gait [29].

A study performed in Spain corroborates the first finding of this study, in which a change in foot posture was observed (decrease in pronation) after elastic tape was applied at 75\% tension. Dynamic assessment also demonstrated a change in forefoot plantar pressure, but tape with no tension caused this change [30]. It is important to underscore that we were unable to correctly identify the profile of the change in foot movement, since the results do not discriminate between the medial and lateral surfaces of each foot segment.

The second finding of this study, namely no effect of tape on the hindfoot, corroborates others, which found no effects from applying elastic tape on foot posture or the hindfoot during gait $[28,29]$. Another study, however, found that elastic taping at $75 \%$ tension changed foot posture and without tension altered hindfoot movement in gait assessment [30].

Another result of the study showed a decline in midfoot arch height after taping, differing from the findings of other articles [28-30]. In these investigations, medial midfoot pressure was observed after elastic tape was used or foot posture was maintained, that is, none of the studies found a decrease in MLA height. In addition, our results showed no intergroup differences, suggesting the need for a larger sample size in order to understand the effect of elastic tape on arch height.

As described in the methods section (variables), MLA height is the distance between the marker at the base of the first metatarsus and the plane formed by three forefoot markers [23]. Analysis of the results show that the forefoot was less everted with the use of the tape, that is, the forefoot plane inclined such that the medial part was elevated. Thus, height decreased when the lowest measure approached the highest, thereby explaining why intragroup comparison revealed that MLA height was lower with the application of the hyperelastic tape.

Our findings should be interpreted with caution, due to the following limitations: a small number of participants, given that the number of subjects was smaller than the sampling size calculated, since 8 of the 18 initial participants left the experiment; the sample consisted of only women; absence of participant and physiotherapist blinding; only the researcher in charge of kinematic assessment was blinded; the groups were not randomized, since the control and experimental group (internal 
control) consisted of the same individuals; no specific reproducibility values were found for the medial longitudinal arch index and the method to obtain this index is indirect; lack of comparison with other techniques, only immediate assessment time; and difficulty comparing our results with previous findings.

Aspects such as the higher number of participants, participants of both sexes and comparisons with other treatment methods (elastic and rigid tape) are stipulated in the Brazilian Registry of Clinical Trials, but could not be complied with as planned due to recruiting and methodological difficulties.

The difficulty in comparing the results is primarily because most studies use percentage to describe how much the tape is stretched at the moment of application; however, this introduces a subjective aspect to the study, since the applicator visually measures the amount of stretching. Similar to a test of the elastic tape material [18], the present study used a quantitative method to measure tape stretching at the moment of application (Newtons) in order to provide better methodological reproducibility.

The forefoot findings stand out, showing a decline in eversion at initial contact, maximum eversion and toe-off. They are highlighted for the following reasons: forefoot assessment in the frontal plane represents good and moderate reproducibility [27] and intra and intergroup comparison demonstrated significant differences, with a large effect size. Thus, we believe that the forefoot differences observed are real and not a result of measuring error.

The decline in forefoot eversion is clinically relevant, since the differences between pre and postapplication were between $3.59^{\circ}$ and $6.19^{\circ}$ and the minimum detectable difference previously reported is $2.4^{\circ}$ in a study using a similar method, but with shod individuals [31]. It is important to underscore that the characteristics of excessive pronation are everted hindfoot, midfoot with a flattened arch and inverted and adducted forefoot $[2,5,6]$. Studies that used the same assessment model as ours compared flat and normal feet. Thus, in order to reduce the characteristics of excessive pronation, an increase in forefoot eversion must occur in a closed kinetic chain. As the results demonstrate, forefoot eversion occurred and this change is not clinically desirable.

The intervention technique used in the present study applied tension on the forefoot (plantar surface) and midpoint (medial surface), pulling the foot in the same direction as the tibialis anterior muscle. Thus, the intervention used would not be adequate, and we suggest the application of tape directing the forefoot segment to eversion, so that in a closed chain it would provide greater support to the medial forefoot, and another tape on the midfoot would supply force to raise the arch.

In this respect, it is suggested that future research investigate the effect of elastic taping using a larger sample size of both sexes. This will make it possible to better understand the effect of the technique on the midfoot and determine whether the tape can support the forefoot medially in a closed chain.

\section{Conclusion}

The hyperelastic tape used increased excessive pronation in the study sample, causing a decline in forefoot eversion during initial contact, and maximum eversion during stance and toe-off. As such, this change is clinically desirable, given that individuals with excessive pronation exhibit a more inverted forefoot. In the midfoot and hindfoot, the tape did not result in significant changes. The findings of the present study should be interpreted with caution, given the small sample size and other limitations.

\section{Acknowledgements}

The authors would like to thank the Centro Estadual de Reabilitação e Readaptação Dr. Henrique Santillo (CRER); the Coordination for the Improvement of Higher Education Personnel (CAPES) - Funding code: 001; and the Graduate Support Program - PROAP (CAPES), which funds were used to purchase materials for the study.

\section{References}

1. Jenkyn TR, Nicol AC. A multi-segment kinematic model of the foot with a novel definition of forefoot motion for use in clinical gait analysis during walking. J Biomech. 2007;40(14):3271-8. 
2. Levinger P, Murley GS, Barton CJ, Cotchett MP, McSweeney SR, Menz HB. A comparison of foot kinematics in people with normal- and flat-arched feet using the $0 x-$ ford Foot Model. Gait Posture. 2010;32(4):519-23.

3. Stolwijk NM, Koenraadt KLM, Louwerens JWK, Grim D, Duysens J, Keijsers NLW. Foot lengthening and shortening during gait: A parameter to investigate foot function? Gait Posture. 2014;39(2):773-7.

4. Horwood AM, Chockalingam N. Defining excessive, over, or hyper-pronation: A quandary. Foot. 2017;31:49-55.

5. Hösl M, Böhm H, Multerer C, Döderlein L. Does excessive flatfoot deformity affect function? A comparison between symptomatic and asymptomatic flatfeet using the Oxford Foot Model. Gait Posture. 2014;39(1):23-8.

6. Kerr CM, Zavatsky AB, Theologis T, Stebbins J. Kinematic differences between neutral and flat feet with and without symptoms as measured by the Oxford Foot Model. Gait Posture. 2019;67:213-8.

7. Teyhen DS, Nelson LA, Koppenhaver SL, Honan LK, McKay AE, Young AR, et al. Impact of foot type on cost of lower extremity injury. Army Medical Research And Materiel Command Fort Detrick Md. 2013;(STO-MP-HFM-228).

8. Song J, Choe K, Neary M, Zifchock RA, Cameron KL, Trepa $\mathrm{M}$, et al. Comprehensive biomechanical characterization of feet in USMA cadets: Comparison across race, gender, arch flexibility, and foot types. Gait Posture. 2018;60:175-80.

9. Neal BS, Griffiths IB, Dowling GJ, Murley GS, Munteanu SE, Smith MMF, et al. Foot posture as a risk factor for lower limb overuse injury: a systematic review and meta-analysis. J Foot Ankle Res. 2014;7(1):55.

10. Di Caprio F, Buda R, Mosca M, Calabrò A, Giannini S. Foot and Lower Limb Diseases in Runners: Assessment of Risk Factors. J Sports Sci Med. 2010;9(4):587-96.

11. Menz HB, Dufour AB, Riskowski JL, Hillstrom HJ, Hannan MT. Planus Foot Posture and Pronated Foot Function are Associated with Foot Pain: The Framingham Foot Study. Arthritis Care Res (Hoboken). 2013;65(12):1991-9.

12. Rath ME, Stearne DJ, Walker CR, Cox JG. Effect of foot type on knee valgus, ground reaction force, and hip muscle activation in female soccer players. J Sport Med Phys Fit. 2016;56(5):546-53.
13. Silva RS, Ferreira ALG, Veronese LM, Driusso P, Serrão FV. Relação entre hiperpronação subtalar e lesões do ligamento cruzado anterior do joelho: revisão de literatura. Fisioter Mov. 2012;25(3):679-88.

14. Bittencourt NFN, Ocarino JM, Mendonça LD, Hewett TE, Fonseca ST. Foot and hip contributions to high frontal plane knee projection angle in athletes: a classification and regression tree approach. J Orthop Sport Phys Ther. 2012;42(12):996-1004.

15. Lack S, Barton C, Malliaras P, Twycross-Lewis R, Woledge $\mathrm{R}$, Morrissey D. The effect of anti-pronation foot orthoses on hip and knee kinematics and muscle activity during a functional step-up task in healthy individuals: A laboratory study. Clin Biomech. 2014;29(2):177-82.

16. Myer GD, Ford KR, Foss KDB, Goodman A, Ceasar A, Rauh $M J$, et al. The incidence and potential pathomechanics of patellofemoral pain in female athletes. Clin Biomech. 2010;25(7):700-7.

17. McNeill W, Pedersen C. Dynamic tape. Is it all about controlling load? J Bodyw Mov Ther. 2016;20(1):179-88.

18. Matheus JPC, Zille RR, Gomide LB, Lemos TV, Carregaro RL, Shimano AC. Comparison of the mechanical properties of therapeutic elastic tapes used in sports and clinical practice. Phys Ther Sport. 2017;24:74-8.

19. Smith MMF, Coates SS, Creaby MW. A comparison of rigid tape and exercise, elastic tape and exercise and exercise alone on pain and lower limb function in individuals with exercise related leg pain: a randomised controlled trial. BMC Musculoskelet Disord. 2014;15(1):328.

20. Redmond A. Foot Posture Index - User guide and manual. 2005 [cited 2019 Oct 30]. Available from: https:// tinyurl.com/yamvm5gm

21. Aquino MR, Avelar BS, Silva PL, Ocarino JM, Resende RA. Reliability of Foot Posture Index individual and total scores for adults and older adults. Musculoskelet Sci Pract. 2018;36:92-5.

22. Stebbins J, Harrington M, Thompson N, Zavatsky A, Theologis T. Repeatability of a model for measuring multi-segment foot kinematics in children. Gait Posture. 2006;23(4):401-10.

23. Vicon Motion Systems Limited. Oxford Foot Model 1.4. 2012 [cited 2019 Sep 15]. Available from: www.vicon. com 
24. Yoho R, Rivera JJ, Renschler R, Vardaxis VG, Dikis J. A biomechanical analysis of the effects of low-Dye taping on arch deformation during gait. Foot. 2012;22(4):283-6.

25. Lakens D. Calculating and reporting effect sizes to facilitate cumulative science: a practical primer for t-tests and ANOVAs. Front Psychol. 2013;4:1-12.

26. Pallant J. SPSS survival manual. 3rd ed. New York: McGraw Hill Open University Press; 2007.

27. van Hoeve S, de Vos J, Weijers P, Verbruggen J, Willems P, Poeze M, et al. Repeatability of the Oxford Foot Model for Kinematic Gait Analysis of the Foot and Ankle. Clin Res Foot Ankle. 2015;3:1-16.

28. Luque-Suarez A, Gijon-Nogueron G, Baron-Lopez FJ, Labajos-Manzanares MT, Hush J, Hancock MJ. Effects of KinesioTaping on foot posture in participants with pronated foot: a quasi-randomised, double-blind study. Physiotherapy. 2014;100(1):36-40.
29. Griebert MC, Needle AR, McConnell J, Kaminski TW. Lower-leg Kinesio tape reduces rate of loading in participants with medial tibial stress syndrome. Phys Ther Sport. 2016;18:62-7.

30. Aguilar MB, Abián-Vicén J, Halstead J, Gijon-Nogueron G. Effectiveness of neuromuscular taping on pronated foot posture and walking plantar pressures in amateur runners. J Sci Med Sport. 2016;19(4):348-53.

31. Milner CE, Brindle RA. Reliability and minimal detectable difference in multisegment foot kinematics during shod walking and running. Gait Posture. 2016;43:192-7.
Received: $11 / 01 / 2019$

Recebido: 01/11/2019

Approved: 05/08/2020

Aprovado: 08/05/2020 